tively rough surface seems to act as a polished mirror toward light striking it at a very small angle of incidence. The mirage on the plains, being a phenomenon of refraction, is of an entirely different nature.

\section{H. H. Platt}

To the Editor of Science : In his communication to the issue of August 27, Mr. F. W. McNair touches upon a matter which seems to me worthy of further consideration.

In the course of numerous trips about the country by automobile, I have had repeated occasion to note the sort of mirage mentioned, particularly on stretches of surfaced road. The phenomenon commonly takes the form of an apparent small pool of water, which appears suddenly a little way ahead, and disappears with equal suddenness.

In most cases the reflecting air-surface would appear to be only a few inches above the road: the effect is that of a shallow pool, and one involuntarily dodges the apparent depression. On one or two occasions, however, I have noted a reflecting surface high enough to cut off the wheels of a vehicle driven through the lower stratum of air.

It occurs to me that the condition suggested may serve in part to account for ideas of temporary disappearance, or dematerialization, of solid objects, and for occasional accounts of apparent hallucination.

This matter would seem to be interesting and important enough to warrant fuller discussion.

Freeman F. Burr

Rattlesnake Island, past which Perry sailed his fleet to the battle of Lake Erie in 1813, lies two miles northwest of Put-in-Bay and occupies about eighteen degrees of the horizon.

On Sunday, July 18, at about one o'clock, while watching a thunderstorm approach over Rattlesnake, a second island was seen, somewhat higher than the real one and shifted to the westward approximately one third the apparent length of the island.

At first this was thought to be a mirage of Middle Sister which lies some miles to the northwest. Two small islets, the Rattles, which lie off shore from the western end of Rattlesnake and which were projected to the left of the phantom island, indicated, however, that we were looking at an image of Rattlesnake.

The apparition was seen from a cottage three hundred yards to the southwest as well as from the laboratory cottage. It persisted for some time, possibly as long as fifteen minutes, disappearing just before the sheets of rain from the storm blotted out Rattlesnake entirely. The outline of the real island was at all times more distinct than that of the image, which was-or seemed to be-slightly behind it as well as above.

$$
\begin{aligned}
& \text { Lake Laboratory, } \\
& \text { Ohio State University, } \\
& \text { Put-in-Bay, Ohio }
\end{aligned}
$$

\section{FAMILY AND SUBFAMILY NAMES IN ZOOLOGY}

To the Editor of ScIEnce: I have read with much interest Oberholser's thirteen rules for family and subfamily names appearing in the issue of ScIEnce of August 13, 1920, which he says have the approval, in part at least, of thirteen named persons well known for their work in systematic zoology. If Dr. Oberholser had stopped with number 12 his rules would appear to be quite ideal.

Why rule 13? Two family or subfamily names having the same spelling are comparatively rare. They are for the most part going to be used by persons who know what the type genera are. It is quite inconceivable that there would ever be any real confusion because of identical spellings. If it is desirable to distinguish between two families or subfamilies that would be spelled alike by following rules 1 and 2, a prefixed Pro seems to me to be the least desirable method. Any one not familiar with the case would naturally think the type genus of Propicidae to be either Propicus or Propica. In Palmer's "Index Generum Mammalium" there are over 100 generic or subgeneric names beginning with the prefix Pro and at least half a dozen of these names are used in forming family or subfamily names. 
The simplest method to distinguish between two family or subfamily names that would otherwise be spelled alike, would seem to be to add idoe or ince to the full generic names in the few cases in which duplication would occur, as Picaidoe and Picusida. Other expedients would be to write $2 \dot{d}$ after the later name, or the year in which the name was published, or the Greek letter $\beta$. To make a prefix as Pro a part of the family or subfamily name and so cause the name to appear in alphabetic lists far away from its logical place and to lead the uninitiated into thinking of a Pro genus which does not exist seems as absurd as it is unnecessary.

M. W. LYoN, JR.

THE NEEDS OF MEN OF SCIENCE IN RUMANIA

To the Editor of Science: Please publish in Science the following extract from a letter of Professor Marinesco, a leading scientist and physician in Rumania.

.... I believe that our American colleagues, whose country made such a noble contribution to victory, ought to take notice of the unhappy state of the Rumanian men of seience which is due to the occupation of our country by the enemy. It is probably unknown that after the occupation we were in extreme distress, because. all our instruments were then taken away or destroyed. A part of our libraries has been destroyed. Furthermore, since Rumania has no chemical industries, we do nat possess the chemical reagents, etc., indispensable for scientific research. Allied European countries which would aid us, France for instance, have been equally devastated.

Perhaps the United States which has contributed so largely to the restoration of Europe would make a grand gesture and help the investigators of our country by sending some instruments and a certain amount of reagents as far as they are able to do so. They can not be accepted gratuitously; but we believe that we will be able to: repay the debt later when the unfavorable exchange no longer weighs so heavily upon our laboratory budgets.

Hoping that my prayer will find a favorable respanse among my American colleagues, we would like you to be our spokesman.

S. J, MeLnzer

ROCKEFELERR INSTMPUNE, NEW YORK, September 1, 1920

\section{QUOTATIONS . SCIENCE AND THE PUBLIC}

THIs is the heading of a leaderette in the Daily Mail, which states that "Light is to be 'caught bending' next week at Cardiff." It goes on to say that "We have in Britain today as original a group of scientific men as any country in the world; and they are beginning at last to see the wisdom of coming out of their eaves and laboratories and applying their brains to practical affairs; to the laws that govern heredity, to wireless apparatus, to the uses of alcohol, to the migration of fish, to medicinal thought-reading, to the possibilities of intensive cultivation-which bulks largely this year-indeed to scores of practical themes to which their more abstract studies are leading.

"In any case, it is time most profitably spent if for one week in the year our men of science bend their united energies to the work of interesting the public in the advance of science. It is as much the duty of the public to appreciate the men of science as of men of science to come to meet the public."

Now, what does the Daily Mail think "our men of science" had been doing during the period before they began to see the wisdom of coming out of their caves and applying their brains to practical affairs? Does it really think that they have suddenly awakened and hurriedly worked up papers on the laws of heredity, on wireless apparatus, etc., just for the purpose of interesting the public during this British Association week?

The Mail speaks of "our men of science" with a patronizing air, a kindly condescension which implies that they are rather weird uncanny folk, not quite normal, who dwell in "caves and laboratories," and do not usually apply their brains to practical affairs-so unlike the brainy trumpeters of the daily press, who gaily talk of "catching light bending" without having the faintest conception of the significance of the allusion. This superior attitude of the journalist who, in many cases, can not even write English correctly, and whose mind is blankly opaque to the most elementary notions of physical science, is galling to those 